\title{
Substratos alternativos ao xaxim na produção de bromélia ornamental
}

\author{
Shoey Kanashiro(1), Keigo Minami(2), Teresa Jocys ${ }^{(3)}$, Carlos Tadeu dos Santos Dias $^{(2)}$ e Armando Reis Tavares ${ }^{(1)}$ \\ (1)Instituto de Botânica, Seção de Ornamentais, Avenida Miguel Stéfano, no 3.687, CEP 04301-902 São Paulo, SP. \\ E-mail: skanashi@uol.com.br, atavares2005 @yahoo.com.br (2)Escola Superior de Agricultura Luiz de Queiroz, Caixa Postal 09, \\ CEP 13418-900 Piracicaba, SP. E-mail: kminami@esalq.usp.br, ctsdias@esalq.usp.br (3)|nstituto Biológico, Avenida Conselheiro Rodrigues \\ Alves, no 1.252, CEP 04014-002 São Paulo, SP. E-mail: tjocys@uol.com.br
}

Resumo - O objetivo deste trabalho foi avaliar substratos alternativos para o cultivo da bromélia Aechmea fasciata (Lindley) Baker, para substituir com eficiência as misturas formuladas com o xaxim Dicksonia sellowiana (Pres1.) Hook. Foram testados os substratos: casca de Pinus, casca de Eucalyptus, coxim, fibra de coco e xaxim, misturados com turfa e perlita, nas proporções 2:7:1, 5:4:1 e 8:1:1. O experimento foi realizado em condições de estufa com cobertura de polietileno, sombreada com tela a 70\%. As bromélias foram cultivadas durante 435 dias, até o início do florescimento - estádio de comercialização. As variáveis analisadas foram as massas de matéria seca de: folhas, raiz, inflorescência, escapo floral e caule; além da massa de matéria seca total e a qualidade comercial. Os substratos formulados com xaxim ou casca de Pinus, nas proporções 2:7:1, 5:4:1 e 8:1:1, e com casca de Eucalyptus, fibra de coco ou coxim, na proporção 2:7:1, foram as misturas que apresentaram os melhores resultados. Os substratos formulados com casca de Eucalyptus, fibra de coco ou coxim, com 10\% de turfa e 10\% de perlita, na proporção 8:1:1, apresentaram os piores resultados.

Termos para indexação: Aechmea fasciata, Dicksonia sellowiana, Bromeliaceae, floricultura.

\section{Alternative substrates to fern tree fiber in the production of ornamental bromeliad}

\begin{abstract}
The objective of this study was to evaluate alternative substrates for the cultivation of the bromeliad Aechmea fasciata (Lindley) Baker, to substitute the formulated mixtures with fern tree fiber from Dicksonia sellowiana (Presl.) Hook. Tested substrates were: Pinus bark, Eucalyptus bark, coxim (made of coconut fiber), coir or fern tree fiber, mixed with peat and perlite, in the proportions $2: 7: 1,5: 4: 1$ and $8: 1: 1$. The experiment was conducted in a greenhouse covered with polyethylene and shaded with shade cloth $70 \%$. The bromeliads were cultivated during 435 days, until the beginning of the flowering, when they were suitable for commercialization. The evaluated parameters were dry masses of leaf, root, inflorescence, floral scape, and stem, besides total dry mass and the commercial quality. The substrates formulated with fern tree fiber or Pinus bark, in the proportions 2:7:1, 5:4:1 and 8:1:1, and with Eucalyptus bark, coir or coxim, in the proportion 2:7:1, showed the best results. The substrates formulated with Eucalyptus bark, coir or coxim in the proportion 8:1:1 presented the poorest results.
\end{abstract}

Index terms: Aechmea fasciata, Dicksonia sellowiana, Bromeliaceae, floriculture.

\section{Introdução}

AfamíliaBromeliaceae apresenta, aproximadamente, 3.086 espécies distribuídas em 58 gêneros (Luther, 2006) e é a maior família das angiospermas, quase exclusivamente neotropical, presente desde o Sul da América do Norte até a Patagônia (Argentina) (Wanderley et al., 2007). Embora apresente grande número de espécies com potencial ornamental, poucas são exploradas economicamente, entre as quais se destaca a Aechmea fasciata (Zimmer, 1985). As bromélias mais utilizadas pelos paisagistas são Alcantarea regina, Aechmea blanchetiana, Neoregelia compacta e Alcantarea imperialis (Vitari, 1994).

Aechmea fasciata (Lindley) Baker é uma espécie nativa do Brasil (Smith, 1955), da subfamília Bromelioideae, e apresenta quatro variedades naturais (Reitz, 1983). Esta foi a primeira bromélia ornamental a ser introduzida para cultivo na Bélgica, no ano de 1836, e ainda é uma das bromeliáceas mais cultivadas 
(Samyn \& Thomas, 1994). Leme (1994) ressaltou que a espécie, assim que foi introduzida, espalhou-se por todos os continentes e tornou-se popular em razão do seu porte elegante, da folhagem atraente e da sua belíssima inflorescência.

As bromélias crescem em profusão, especialmente na Mata Atlântica, e seu cultivo ganhou impulso recentemente entre os produtores rurais, pois é atividade economicamente rentável e boa opção para floricultura. A cultura de bromélias carece de informações técnicas que possam promover o incremento da produtividade $\mathrm{e}$ da qualidade dessas plantas. Entre as dificuldades que os produtores têm enfrentado com freqüência, está a utilização de substrato adequado, deve-se ressaltar que o xaxim Dicksonia sellowiana, um dos componentes utilizados na formulação de substratos para o cultivo de muitas plantas ornamentais envasadas, é considerado uma espécie em perigo de extinção, e sua comercialização é proibida conforme a lei estadual número 11.754 (São Paulo, 2004).

Kämpf(1992) considerou que o cultivo das bromélias (epífitas) exige substratos de baixa densidade, alta permeabilidade e aeração, e que a presença de elevada fração de matéria orgânica no meio de cultivo pode melhorar tais propriedades, enquanto Dimmitt (1992) ressaltou que os substratos para as bromélias deveriam ser ácidos, com alta capacidade de campo, boa drenagem e aeração.

Com relação aos substratos para bromeliáceas, Bunt (1976) formulou a mistura denominada "Cornell epiphyte mix" para plantas que requerem boa drenagem e aeração, como as bromélias epífitas. Wall (1988) recomendou, para a maioria das bromélias, substrato que contenha areia grossa, turfa de esfagno e terra vegetal, em volumes iguais, o que proporciona a drenagem necessária. Para as bromélias epífitas, Williams \& Hodgson (1990) recomendaram a mistura em volumes iguais de turfa de esfagno, areia grossa e pedriscos hortícolas, e uma porção de casca de pinheiro em forma de lascas, para melhorar a drenagem.

Rodrigues et al. (2004) observaram melhores respostas de crescimento de Alcantarea imperialis, no substrato constituído de $50 \%$ de terra de subsolo e 50\% de casca de arroz carbonizada.

$\mathrm{O}$ presente estudo teve como objetivo avaliar substratos alternativos para o cultivo de Aechmea fasciata, para substituir com eficiência os substratos formulados com xaxim.

\section{Material e Métodos}

O experimento foi desenvolvido na área experimental do Departamento de Produção Vegetal da Escola Superior de Agricultura Luiz de Queiroz da Universidade de São Paulo, em Piracicaba, SP. O experimento foi conduzido de julho de 1997 a setembro de 1998 , com temperatura média mensal máxima de $28,35^{\circ} \mathrm{C}$ e mínima de $15,69^{\circ} \mathrm{C}$, e umidade relativa média mensal de $79,63 \%$. Para o desenvolvimento desta pesquisa, foram utilizadas mudas de $A$. fasciata, com idade de 81 dias, obtidas a partir de cultura de meristemas, com 6,53 folhas, altura de $3,72 \mathrm{~cm}$, maior diâmetro da roseta de $11,46 \mathrm{~cm}$ e terceira folha com $1,32 \mathrm{~cm}$ de largura.

$\mathrm{Na}$ primeira etapa, as plantas foram cultivadas em vasos de plástico, com diâmetro de $10 \mathrm{~cm}$ na parte superior, $7,7 \mathrm{~cm}$ na parte inferior e $7,5 \mathrm{~cm}$ de altura $(0,45 \mathrm{~L})$ e, após 5 meses, foram transferidas para vasos de plástico com $15 \mathrm{~cm}$ de diâmetro na parte superior, $10,5 \mathrm{~cm}$ na parte inferior e $12,5 \mathrm{~cm}$ de altura $(1,25 \mathrm{~L})$.

Os substratos utilizados, em ambas as etapas, foram cascas de Pinus (compostadas e com 6-10 mm de comprimento), cascas de Eucalyptus (compostadas e não peneiradas), fibras de coco (não compostadas e peneiradas em malha de $2,5 \mathrm{~cm}$ ), coxim (cubos de

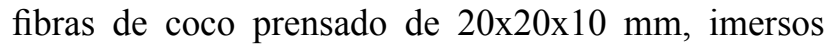
durante 8 dias em água, com renovação diária), perlita de uso agrícola ( 80 a $140 \mathrm{~kg} \mathrm{~m}^{-3}$, com granulometria fina), turfa (peneirada em malha de $4 \mathrm{~cm}$ ) e fibras de xaxim (peneiradas em malha de 2,5 cm). Os substratos foram formulados conforme a Tabela 1, e as análises das propriedades físicas e químicas (Fretz et al., 1979) dos substratos encontram-se nas Tabelas 1 e 2.

A adubação foi realizada no substrato, com $50 \mathrm{~mL}$ de solução $(0,2 \%$ de $15: 5: 30)$ por planta durante a primeira etapa de cultivo, e $170 \mathrm{~mL}$ por planta durante a segunda etapa de cultivo. Depois disso foram feitas adubações foliares semanais $(0,1 \%$ de $7: 17: 35)$. O cultivo foi realizado em estufa com $70 \%$ de sombreamento, e a irrigação foi semanal, por microaspersão.

As bromélias foram induzidas ao florescimento, aos 375 dias, pela aplicação no centro da roseta, de $135 \mathrm{~mL}$ da solução de ácido 2-cloroetil fosfônico (Etephon $240 \mathrm{~g} \mathrm{~L}^{-1}$ ), à concentração de $800 \mathrm{~mL} \mathrm{~L}^{-1}$, conforme Mele-Grau \& Messeguer-Peypoch (1980).

Ao final do experimento, aos 435 dias, foram avaliadas as variáveis de massa de matéria seca de: folhas, inflorescência, escapo floral, raízes, caule e total. 
A qualidade comercial das plantas foi avaliada (um avaliador) com um sistema de notas, que variou de 1 a 3 , em que as plantas foram analisadas individualmente, segundo os critérios: 1, plantas sem defeitos que comprometessem a qualidade comercial, tanto nas folhas como na inflorescência; 2, plantas com defeitos leves (má formação da roseta e de inflorescência) que comprometessem a qualidade comercial, tanto nas folhas como na inflorescência; e 3, plantas com defeitos graves (má fixação nos vasos), sem condições de comercialização.

O delineamento experimental adotado foi o de blocos ao acaso, conforme Nogueira (2007), com 15 tratamentos e 4 blocos, em que cada parcela foi constituída por 8 plantas. Na avaliação da massa das plantas e qualidade comercial, foram consideradas seis plantas por parcela. Para cálculo da variável massa de matéria seca da raiz, foram analisadas 3 plantas por parcela. O teste qui-quadrado, para se verificar a independência entre os 15 tratamentos e as notas atribuídas, forneceu o valor do $\chi^{2}{ }_{\text {obs }}$.

\section{Resultados e Discussão}

As maiores médias para a produção de matéria seca da folha (Tabela 3) foram proporcionadas pelos substratos que continham xaxim ou casca de Pinus; os substratos fibra de coco e casca de Eucalyptus, nas proporções

Tabela 1. Composição dos substratos, proporção entre os componentes e características físicas dos substratos utilizados no cultivo de Aechmea fasciata em vaso.

\begin{tabular}{|c|c|c|c|c|c|c|}
\hline Substrato $^{(1)}$ & Composição & $\begin{array}{c}\text { Proporção } \\
\text { volumétrica }\end{array}$ & $\begin{array}{c}\text { Densidade } \\
\left(\mathrm{g} \mathrm{mL}^{-1}\right)\end{array}$ & $\begin{array}{c}\text { Espaço poroso } \\
\text { total } \\
(\mathrm{mL})\end{array}$ & $\begin{array}{l}\text { Água retida à } \\
\text { capacidade de } \\
\text { campo }(\mathrm{mL})\end{array}$ & $\begin{array}{c}\text { Espaço poroso à } \\
\text { capacidade de } \\
\text { campo }(\mathrm{mL})\end{array}$ \\
\hline $\mathrm{Pi} / 2: 7: 1$ & Casca de Pinus + turfa + perlita & $2: 7: 1$ & 0,30 & 133,67 & 105,60 & 28,07 \\
\hline $\mathrm{Pi} / 5: 4: 1$ & Casca de Pinus + turfa + perlita & $5: 4: 1$ & 0,29 & 137,67 & 104,42 & 33,25 \\
\hline $\mathrm{Pi} / 8: 1: 1$ & Casca de Pinus + turfa + perlita & $8: 1: 1$ & 0,27 & 118,67 & 75,42 & 43,24 \\
\hline $\mathrm{Eu} / 2: 7: 1$ & Casca de Eucalyptus + turfa + perlita & $2: 7: 1$ & 0,31 & 148,67 & 127,54 & 21,12 \\
\hline $\mathrm{Eu} / 5: 4: 1$ & Casca de Eucalyptus + turfa + perlita & $5: 4: 1$ & 0,33 & 137,17 & 125,45 & 11,71 \\
\hline $\mathrm{Eu} / 8: 1: 1$ & Casca de Eucalyptus + turfa + perlita & $8: 1: 1$ & 0,44 & 99,00 & 87,21 & 11,79 \\
\hline $\mathrm{Cx} / 2: 7: 1$ & Coxim + turfa + perlita & $2: 7: 1$ & 0,34 & 132,00 & 106,34 & 25,66 \\
\hline $\mathrm{Cx} / 5: 4: 1$ & Coxim + turfa + perlita & $5: 4: 1$ & 0,32 & 129,36 & 100,65 & 28,71 \\
\hline $\mathrm{Cx} / 8: 1: 1$ & Coxim + turfa + perlita & $8: 1: 1$ & 0,30 & 136,67 & 79,01 & 21,16 \\
\hline$\overline{\mathrm{Fc} / 2: 7: 1}$ & Fibra de coco + turfa + perlita & $2: 7: 1$ & 0,31 & 121,33 & 109,51 & 11,82 \\
\hline $\mathrm{Fc} / 5: 4: 1$ & Fibra de coco + turfa + perlita & $5: 4: 1$ & 0,26 & 104,33 & 82,14 & 22,19 \\
\hline $\mathrm{Fc} / 8: 1: 1$ & Fibra de coco + turfa + perlita & $8: 1: 1$ & 0,07 & 152,67 & 16,24 & 32,09 \\
\hline $\mathrm{Xa} / 2: 7: 1$ & Xaxim + turfa + perlita & $2: 7: 1$ & 0,27 & 145,83 & 126,99 & 18,84 \\
\hline $\mathrm{Xa} / 5: 4: 1$ & Xaxim + turfa + perlita & $5: 4: 1$ & 0,20 & 120,33 & 107,65 & 12,68 \\
\hline $\mathrm{Xa} / 8: 1: 1$ & Xaxim + turfa + perlita & $8: 1: 1$ & 0,17 & 108,33 & 79,37 & 28,97 \\
\hline
\end{tabular}

${ }^{(1)} \mathrm{Pi}$, casca de Pinus; Eu, casca de Eucalyptus; Cx, coxim; Fc, fibra de coco; Xa, xaxim; os números após as barras indicam a proporção entre os substratos, a turfa e a perlita.

Tabela 2. Análise química dos substratos com casca de Pinus (Pi), casca de Eucalyptus (Eu), coxim (Cx), fibra de coco (Fc) e xaxim (Xa), misturados com turfa e perlita, nas proporções 2:7:1, 5:4:1 e 8:1:1, utilizados no experimento com a espécie Aechmea fasciata ${ }^{(1)}$.

\begin{tabular}{|c|c|c|c|c|c|c|c|c|c|c|c|c|c|c|c|}
\hline Determinação & $\mathrm{Pi} / 2: 7: 1$ & $\mathrm{Pi} / 5: 4: 1$ & $\mathrm{Pi} / 8: 1: 1$ & $\mathrm{Eu} / 2: 7: 1$ & $\mathrm{Eu} / 5: 4: 1$ & $\mathrm{Eu} / 8: 1: 1$ & $\mathrm{Cx} / 2: 7: 1$ & $\mathrm{Cx} / 5: 4: 1$ & $\mathrm{Cx} / 8: 1: 1$ & $\mathrm{Fc} / 2: 7: 1$ & $\mathrm{Fc} / 5: 4: 1$ & $\mathrm{Fc} / 8: 1: 1$ & $\mathrm{Xa} / 2: 7: 1$ & $\mathrm{Xa} / 5: 4: 1$ & $\mathrm{Xa} / 8: 1: 1$ \\
\hline $\mathrm{pH}$ em $\mathrm{CaCl}_{2}$ & 3,40 & 3,30 & 3,40 & 4,20 & 5,20 & 6,30 & 3,60 & 4,10 & 4,80 & 3,60 & 3,50 & 4,00 & 3,40 & 3,40 & 3,30 \\
\hline Umidade total $(\%)$ & 15,82 & 18,00 & 15,85 & 14,11 & 14,81 & 38,52 & 20,77 & 17,56 & 18,30 & 14,57 & 30,07 & 16,11 & 22,20 & 16,20 & 40,67 \\
\hline MO total (\%) & 67,26 & 72,55 & 68,15 & 66,70 & 66,88 & 40,70 & 64,43 & 64,25 & 65,49 & 64,20 & 52,81 & 78,52 & 60,36 & 68,25 & 50,76 \\
\hline $\mathrm{C}$ total $(\%)$ & 37,37 & 40,30 & 37,86 & 37,06 & 37,15 & 22,61 & 35,79 & 35,70 & 36,38 & 35,67 & 29,34 & 43,62 & 33,53 & 37,91 & 28,20 \\
\hline $\mathrm{N}$ total $(\%)$ & 1,04 & 0,60 & 0,37 & 1,06 & 0,74 & 0,67 & 0,75 & 0,54 & 0,29 & 1,05 & 0,86 & 0,25 & 1,12 & 0,97 & 0,51 \\
\hline $\mathrm{P}\left(\mathrm{P}_{2} \mathrm{O}_{5}\right)$ total $(\%)$ & 0,02 & 0,02 & 0,02 & 0,02 & 0,02 & 0,01 & 0,02 & 0,02 & 0,02 & 0,02 & 0,01 & 0,02 & 0,02 & 0,02 & 0,01 \\
\hline $\mathrm{K}\left(\mathrm{K}_{2} \mathrm{O}\right) \mathrm{t}$ & 0,04 & 0,04 & 0,04 & 0,06 & 0,07 & 0,10 & 0,11 & 0,19 & 4,19 & 0,04 & 0,03 & 0,02 & 0,04 & 0,06 & 0,05 \\
\hline Ca total ( & 1,00 & 0,26 & 0,19 & 0,60 & 1,14 & 1,64 & 0,32 & 0,28 & 0,23 & 1,33 & 0,22 & 0,13 & 0,19 & 0,19 & 0,17 \\
\hline $\operatorname{Mg}(\%)$ & 0,09 & 0,06 & 0,05 & 0,11 & 0,15 & 0,16 & 0,11 & 0,12 & 0,11 & 0,75 & 0,12 & 0,07 & 0,10 & 0,08 & 0,05 \\
\hline $\mathrm{S}$ total $(\%)$ & 0,07 & 0,04 & 0,05 & 0,02 & 0,04 & 0,02 & 0,04 & 0,16 & 0,03 & 0,04 & 0,03 & 0,02 & 0,01 & 0,02 & 0,01 \\
\hline $\mathrm{C}$ total $/ \mathrm{N}$ total & 36 & 68 & 103 & 35 & 50 & 34 & 48 & 66 & 124 & 34 & 34 & 178 & 30 & 39 & 55 \\
\hline $\mathrm{C}$ org. $/ \mathrm{N}$ total & 35 & 57 & 89 & 35 & 48 & 31 & 42 & 66 & 120 & 34 & 34 & 176 & 27 & 33 & 53 \\
\hline
\end{tabular}

${ }^{(1)}$ Os números após as barras indicam a proporção entre os substratos, a turfa e a perlita. 
2:7:1, não diferiram significativamente. Nos substratos compostos de fibra de coco ou casca de Eucalyptus, na proporção 2:7:1, a maior quantidade de turfa nas formulações compensou a menor proporção de fibra de coco ou casca de Eucalyptus, enquanto os substratos com xaxim ou casca de Pinus, independentemente das diferentes formulações, apresentaram resultados semelhantes. A fibra de coco apresenta baixa condutividade elétrica e baixos teores de nutrientes e sais; portanto, para ser eficiente como substrato, deverá ser empregada em mistura com outros materiais mais ricos em nutrientes (Silveira et al., 2002).

As menores produções de matéria seca da folha (Tabela3) foram encontradas em substratos constituídos de casca de Eucalyptus, coxim ou fibra de coco, na proporção 8:1:1; neste caso, a menor proporção de turfa pode ter sido a causa da baixa produtividade. Resultados semelhantes foram obtidos por D'Andréa \& Demattê (2000), em que a adição do componente orgânico húmus (10\%) aos substratos foi mais benéfica ao crescimento de Aechmea fasciata do que a adição de vermiculita e pedaços de cerâmica; segundo os autores, a espécie tem o melhor crescimento, quando os nutrientes estão disponíveis para as raízes.

Na variável massa de matéria seca do caule (Tabela 3), os substratos formulados com xaxim ou casca de Pinus - em todas as proporções -, e os substratos com casca de Eucalyptus, fibra de coco ou coxim - na proporção 2:7:1 -, bem como os substratos com casca de Eucalyptus ou coxim - na proporção 5:4:1 -, não diferiram significativamente entre si e apresentaram as maiores médias. Os substratos formulados com casca de Eucalyptus ou coxim na proporção 8:1:1 e com fibra de coco nas proporções 5:4:1 e 8:1:1 mostraram a menor produção de matéria seca de caule, provavelmente, em razão da menor proporção de turfa, que foi de $10 \%$ em volume.

As menores médias de produção de matéria seca de escapo floral (Tabela 3) foram obtidas nos substratos formulados com coxim, casca de Eucalyptus ou fibra de coco, na proporção 8:1:1. A deficiência desses substratos parece estar relacionada à menor quantidade de turfa em suas formulações. Resultados semelhantes foram observados por D'Andréa \& Demattê (2000), quando compararam misturas compostas de xaxim, casca de coco e Pinus, bagaço de cana-de-açúcar, cacos de cerâmica, vermiculita e húmus, para a utilização de substratos alternativos em substituição ao xaxim, no cultivo de $A$. fasciata. Esses autores relataram que os substratos constituídos de $45 \%$ de xaxim, $45 \%$ de casca de Pinus e $10 \%$ de húmus e de $45 \%$ de xaxim, $45 \%$ de casca de coco e $10 \%$ de húmus foram os mais eficientes. Dos substratos que não continham xaxim, o substrato com $45 \%$ de casca de coco, $45 \%$ de casca

Tabela 3. Médias da massa de matéria seca de folha, raiz, inflorescência, escapo floral, caule e total da espécie Aechmea fasciata $^{(1)}$.

\begin{tabular}{|c|c|c|c|c|c|c|}
\hline \multirow[t]{2}{*}{ Tratamento $^{(2)}$} & \multicolumn{6}{|c|}{ Massa de matéria seca $(\mathrm{g})$} \\
\hline & Folha & Caule & Escapo floral & Inflorescência & Raiz & Total \\
\hline $\mathrm{Pi} / 2: 7: 1$ & $71,01 \mathrm{ab}$ & $5,24 a b c$ & 2,64abcd & $5,54 \mathrm{abc}$ & $3,22 b c$ & $89,16 a b c$ \\
\hline $\mathrm{Pi} / 5: 4: 1$ & $72,10 \mathrm{ab}$ & $5,30 \mathrm{abc}$ & $2,77 \mathrm{ab}$ & $6,07 \mathrm{ab}$ & $3,74 \mathrm{ab}$ & $91,54 \mathrm{a}$ \\
\hline $\mathrm{Pi} / 8: 1: 1$ & $72,10 \mathrm{ab}$ & $5,28 \mathrm{abc}$ & $2,93 a$ & $6,10 \mathrm{ab}$ & $4,56 \mathrm{a}$ & $91,41 \mathrm{ab}$ \\
\hline $\mathrm{Eu} / 2: 7: 1$ & $71,23 \mathrm{ab}$ & $5,50 \mathrm{ab}$ & $3,02 \mathrm{a}$ & $6,68 \mathrm{a}$ & $3,21 b c$ & $86,50 \mathrm{abcd}$ \\
\hline $\mathrm{Eu} / 5: 4: 1$ & $62,96 \mathrm{~cd}$ & $5,27 \mathrm{abc}$ & 2,59abcd & $5,73 \mathrm{ab}$ & $2,91 b c$ & $79,61 \mathrm{bcd}$ \\
\hline $\mathrm{Eu} / 8: 1: 1$ & $51,91 \mathrm{e}$ & 4,81 bcde & $2,14 \mathrm{~cd}$ & $5,20 \mathrm{bcd}$ & $3,03 \mathrm{bc}$ & $66,86 \mathrm{efg}$ \\
\hline $\mathrm{Cx} / 2: 7: 1$ & $68,33 \mathrm{bcd}$ & $5,25 \mathrm{abc}$ & $2,82 \mathrm{ab}$ & $6,04 \mathrm{ab}$ & $3,25 b c$ & $85,94 \mathrm{abcd}$ \\
\hline $\mathrm{Cx} / 5: 4: 1$ & $61,07 d$ & $4,98 \mathrm{abcd}$ & $2,67 \mathrm{abc}$ & $5,21 \mathrm{bcd}$ & $2,84 \mathrm{bc}$ & 77,39 cde \\
\hline $\mathrm{Cx} / 8: 1: 1$ & $49,06 \mathrm{e}$ & $4,37 \mathrm{de}$ & $2,30 \mathrm{bcd}$ & $4,24 \mathrm{~cd}$ & $2,61 \mathrm{c}$ & $64,30 f g$ \\
\hline $\mathrm{Fc} / 2: 7: 1$ & $70,24 \mathrm{abc}$ & $5,33 \mathrm{abc}$ & $2,81 \mathrm{ab}$ & $5,95 \mathrm{ab}$ & $3,19 b c$ & $87,40 \mathrm{abcd}$ \\
\hline $\mathrm{Fc} / 5: 4: 1$ & $60,95 d$ & $4,59 \mathrm{cde}$ & $2,53 \mathrm{abcd}$ & $5,08 \mathrm{bcd}$ & $3,10 \mathrm{bc}$ & $76,19 \mathrm{def}$ \\
\hline $\mathrm{Fc} / 8: 1: 1$ & $46,81 \mathrm{e}$ & $4,00 \mathrm{e}$ & $2,08 \mathrm{~d}$ & $4,07 \mathrm{~d}$ & $2,54 \mathrm{c}$ & $58,49 \mathrm{~g}$ \\
\hline $\mathrm{Xa} / 2: 7: 1$ & $71,63 \mathrm{ab}$ & $5,61 \mathrm{ab}$ & 2,49abcd & $5,33 \mathrm{abcd}$ & $3,06 \mathrm{bc}$ & 86,99abcd \\
\hline $\mathrm{Xa} / 5: 4: 1$ & $77,03 \mathrm{a}$ & $5,78 \mathrm{a}$ & $3,04 \mathrm{a}$ & $6,48 \mathrm{ab}$ & $3,20 b c$ & $93,97 a$ \\
\hline $\mathrm{Xa} / 8: 1: 1$ & $74,53 \mathrm{ab}$ & $5,71 \mathrm{a}$ & 2,61 abcd & $5,17 \mathrm{bcd}$ & $3,75 \mathrm{ab}$ & $91,10 \mathrm{ab}$ \\
\hline Média geral & 65,40 & 5,13 & 2,63 & 5,52 & 3,22 & 81,79 \\
\hline DMS (5\%) & 7,59 & 0,80 & 0,58 & 1,40 & 1,11 & 11,90 \\
\hline CV $(\%)$ & 4,56 & 6,17 & 8,69 & 9,99 & 13,57 & 5,71 \\
\hline
\end{tabular}

${ }^{(1)}$ Médias seguidas por letras iguais, nas colunas, não diferem significativamente entre si, pelo teste de Tukey, a 5\% de probabilidade. ${ }^{(2)} \mathrm{Pi}$, casca de Pinus; Eu, casca de Eucalyptus; Cx, coxim; Fc, fibra de coco; Xa, xaxim; DMS, diferença mínima significativa; CV, coeficiente de variação; os números após as barras indicam a proporção entre os substratos, a turfa e a perlita. 
de Pinus e $10 \%$ de húmus apresentou os melhores resultados; portanto, a adição de $10 \%$ de húmus foi benéfica para as misturas formuladas.

As maiores médias de produção de matéria seca de inflorescência (Tabela 3) foram obtidas com os substratos formulados com casca de Pinus, em todas as proporções testadas, e com os de xaxim ou casca de Eucalyptus - nas proporções 2:7:1 e 5:4:1 -, e fibra de coco ou coxim - na proporção $2: 7: 1$. Os substratos coxim 8:1:1 e fibra de coco 8:1:1 apresentaram as menores médias, o que é indicação de que os substratos formulados à base coxim ou fibra de coco, com menor proporção de turfa foram, provavelmente, influenciados pela menor quantidade desta.

Os substratos com casca de Pinus ou xaxim na proporção 8:1:1 e Pinus 5:4:1 apresentaram os melhores resultados na produção de matéria seca da raiz (Tabela 3). A menor produção de matéria seca da raiz foi obtida com os substratos coxim 8:1:1 e fibra de $\operatorname{coco} 8: 1: 1$.

Os substratos formulados com xaxim ou casca de Pinus, em todas as proporções experimentadas, e os substratos constituídos de fibra de coco, casca de Eucalyptus ou coxim, na proporção 2:7:1, apresentaram as maiores médias de produção de matéria seca total (Tabela 3). Os substratos constituídos de casca de Eucalyptus, coxim e fibra de coco, na proporção $8: 1: 1$, apresentaram a menor produção de matéria seca total, porém, os resultados estão relacionados à menor proporção de turfa. Outro fator que pode ter influenciado na menor produção de matéria seca total, dos substratos coxim e fibra de coco na proporção $8: 1: 1$, foi a alta relação $\mathrm{C} / \mathrm{N}$. O substrato fibra de coco 8:1:1 apresentou ainda baixa capacidade de campo, o que contribuiu para o menor rendimento da produção de matéria seca. Porém, Demattê (2005) concluiu que a espécie de bromélia Tillandsia kautskyi pode ser cultivada em substrato com $100 \%$ de fibra de coco, em substituição ao xaxim. Da mesma forma, Jasmin et al. (2006) relataram que a fibra de coco pode ser alternativa ao uso do xaxim no cultivo da bromélia Cryptanthus sinuosus, o que melhora a arquitetura (diâmetro e disposição) e proporciona coloração mais atrativa às folhas, embora apresente menor número de folhas e menor massa de matéria seca.

As freqüências observadas da qualidade comercial, avaliada por meio do critério de notas, estão apresentadas na Tabela 4. A hipótese de independência entre os 15 tratamentos e as notas atribuídas foi rejeitada pelo teste qui-quadrado $\left(\chi_{\text {obs }}^{2}=210,40\right)$, significativo a $1 \%$ de probabilidade, o que indica a existência de diferença entre os tratamentos, com relação à variável qualidade comercial. Os substratos xaxim 5:4:1, Pinus 5:4:1, fibra de coco 2:7:1 e Pinus 8:1:1 destacaram-se no aspecto qualidade comercial. A seguir, salientaram-se os substratos formulados com casca de Pinus, Eucalyptus ou coxim, na proporção 2:7:1, e xaxim 8:1:1; e, em posição intermediária, os substratos com casca de Eucalyptus, fibra de coco ou coxim, na proporção 5:4:1. Portanto, pode-se inferir que as plantas cultivadas nos substratos formulados com xaxim ou casca de Pinus, em todas as proporções, e os substratos com casca de Eucalyptus, fibra de coco ou coxim, nas proporções $2: 7: 1$ e 5:4:1, apresentaram maior freqüência de notas 3 e 2 . As plantas cultivadas em substrato com casca de Eucalyptus, coxim ou fibra de coco, todos na proporção 8:1:1, apresentaram as piores notas; observou-se que esses substratos foram formulados com maior proporção de casca de Eucalyptus, coxim ou fibra de coco e menor quantidade de turfa.

Os substratos formulados com xaxim ou casca de Pinus nas proporções 2:7:1, 5:4:1 e 8:1:1, e casca de Eucalyptus, fibra de coco ou coxim, na proporção 2:7:1, foram as misturas que apresentaram os melhores

Tabela 4. Resultados do teste de $\chi^{2}$ para a variável qualidade comercial, comparando-se os tratamentos dois a dois, na espécie Aechmea fasciata.

\begin{tabular}{lrrr}
\hline Tratamento $^{(1)}$ & \multicolumn{3}{c}{ Nota de qualidade comercial } \\
\cline { 2 - 4 } & 3 & 2 & 1 \\
\hline $\mathrm{Xa} / 5: 4: 1 \mathrm{a}$ & 24 & 0 & 0 \\
$\mathrm{Pi} / 5: 4: 1 \mathrm{ab}$ & 23 & 1 & 0 \\
$\mathrm{Fc} / 2: 7: 1 \mathrm{abc}$ & 21 & 3 & 0 \\
$\mathrm{Pi} / 2: 7: 1 \mathrm{bc}$ & 20 & 4 & 0 \\
$\mathrm{Eu} / 2: 7: 1 \mathrm{bc}$ & 20 & 4 & 0 \\
$\mathrm{Pi} / 8: 1: 1 \mathrm{abc}$ & 19 & 4 & 1 \\
$\mathrm{Cx} / 2: 7: 1 \mathrm{bc}$ & 19 & 5 & 0 \\
$\mathrm{Xa} / 8: 1: 1 \mathrm{bc}$ & 19 & 5 & 0 \\
$\mathrm{Xa} / 2: 7: 1 \mathrm{~cd}$ & 14 & 8 & 2 \\
$\mathrm{Eu} / 5: 4: 1 \mathrm{de}$ & 10 & 10 & 4 \\
$\mathrm{Fc} / 5: 4: 1 \mathrm{~d}$ & 10 & 14 & 0 \\
$\mathrm{Cx} / 5: 4: 1 \mathrm{de}$ & 9 & 12 & 3 \\
$\mathrm{Eu} / 8: 1: 1 \mathrm{ef}$ & 4 & 10 & 10 \\
$\mathrm{Cx}: 8: 1: 1 \mathrm{f}$ & 0 & 11 & 13 \\
$\mathrm{Fc} / 8: 1: 1 \mathrm{f}$ & 0 & 11 & 13 \\
\hline
\end{tabular}

${ }^{(1)}$ Tratamentos seguidos de letras iguais não diferem entre si pelo teste de $\chi^{2}$, a $5 \%$ de probabilidade; Pi, casca de Pinus; Eu, casca de Eucalyptus; Cx, coxim; Fc, fibra de coco; Xa, xaxim; os números após as barras indicam a proporção entre os substratos, a turfa e a perlita. 
resultados. Os substratos formulados com casca de Eucalyptus, fibra de coco ou coxim, na proporção $8: 1: 1$, apresentaram os menores valores quanto à massa de matéria seca em Aechmea fasciata.

\section{Conclusão}

Casca de Pinus, nas proporções 2:7:1, 5:4:1 e 8:1:1, casca de Eucalyptus, fibra de coco ou coxim, na proporção 2:7:1, são os substratos que podem substituir com eficiência as misturas com xaxim.

\section{Agradecimentos}

Ao Conselho Nacional de Desenvolvimento Científico e Tecnológico, por concessão de bolsa.

\section{Referências}

BUNT, A.C. Modern potting composts: a manual on the preparation and use of growing media for pot plants. London: George Allen \& Unwin, 1976. 277p.

D'ANDRÉA, J.C.; DEMATTÊ, M.E.S.P. Effect of growing media and fertilizer on the early growth of Aechmea fasciata Bak. Acta Horticulturae, v.511, p.271-275, 2000.

DEMATTÊ, M.E.S.P. Cultivo de Tillandsia kautskyi E. Pereira, bromélia brasileira em risco de extinção: comparação de substratos. Revista Brasileira de Horticultura Ornamental, v.11, p.114-120, 2005.

DIMMITT, M.A. Bromeliads: a cultural manual. Oregon: The Bromeliad Society, 1992. 42p.

FRETZ, T.A.; READ, P.E.; PEELE, M.C. Plant propagation lab manual. ${ }^{\text {rd }}$ ed. Minneapolis: Burges Publishing, 1979. 317p.

JASMIM, J.M.; TOLEDO, R.R.V.; CARNEIRO, L.A.; MANSUR, E. Fibra de coco e adubação foliar no crescimento e nutrição de Cryptanthus sinuosus. Horticultura Brasileira, v.24, p.309-314, 2006.

KÄMPF, A.N. Bromélias. In: CASTRO, C.E.F. de; ANGELIS, B.L.D. de; MOURA, L.P.P. de; SILVEIRA, R.B.A.; ANGELIS NETO, G.; SATO, N.T. de (Coord.). Manual de floricultura. Maringá: UEM, 1992. p.201-211.
LEME, E.M.C. Aechmea fasciata, o símbolo da Sociedade Brasileira de Bromélias. Bromélia, v.1, p.34-35, 1994.

LUTHER, H.E. An alphabetical list of bromeliad binomial. 10.ed. Sarasota: The Marie Selby Botanical Gardens, 2006. 119p.

MELE-GRAU, E.; MESSEGUER-PEYPOCH, J. Estudio de algunos aspectos del cultivo de Aechmea fasciata (Back.). Anales del Instituto Nacional de Investigaciones Agrarias, v.12, p.133-155, 1980.

NOGUEIRA, M.C.S. Experimentação agronômica I: conceito, planejamento e análise estatística. Piracicaba: Esalq, 2007. 479p.

REITZ, R. Bromeliáceas e malária-bromélia endêmica. Itajaí: Herbário Barbosa Rodrigues, 1983. 808p.

RODRIGUES, T.M.; PAIVA, P.D. de O.; RODRIGUES, C.R.; CARVALHO, J.G. de; FERREIRA, C.A.; PAIVA, R. Desenvolvimento de mudas de bromélia-imperial (Alcantarea imperialis) em diferentes substratos. Ciência e Agrotecnologia, v.28, p.757-763, 2004.

SAMYN, G.; THOMAS, F. The Belgians and bromeliads: part I, the $19^{\text {th }}$ century: Belgium becomes an horticultural nation. Bromelia, v.1, p.3-8, 1994

SÃO PAULO (Estado). Lei Estadual no 11.754, de 1ㅇ de junho de 2004. Dispõe sobre a industrialização e a comercialização de produtos que especifica. Diário Oficial do Estado, São Paulo, 2 jul. 2004. p.1.

SILVEIRA, E.B.; RODRIGUES, V.J.L.B.; GOMES, A.M.A.; MARIANO, R.L.R.; MESQUITA, J.C.P. Pó de coco como substrato para produção de mudas de tomateiro. Horticultura Brasileira, v.20, p.211-216, 2002.

SMITH, L.B. The Bromeliaceae of Brazil. Washington: Smithonian Institute. 1955. 290p. (Smithsonian Miscellaneous Collections, v.126).

VITARI, M. Bromélia: produção e proteção. Ecologia e Desenvolvimento, v.3, p.15-17, 1994.

WALL, B. Bromeliads. London: Cassel for the Royal Horticultural Society, 1988. 64p.

WANDERLEY, M.G.L.; SHEPHERD, G.J.; MELHEM, T.S.; GIULIETTI, A.M. Flora fanerogâmica do Estado de São Paulo. São Paulo: Instituto de Botânica, 2007. v.5. 476p.

WILLIAMS, B.; HODGSON, I. Growing bromeliads. London: Christopher Helm, 1990. 150p.

ZIMMER, K. Bromeliaceae (ornamentals). In: HALEVY, A.H. CRC handbook of flowering. Boca Raton: CRC Press, 1985. p.78-81. 